\title{
Molecular and granular characteristics of corn starch modified by HCl-methanol at different temperatures
}

\author{
Yi-Lin Chung, Hsi-Mei Lai* \\ Department of Agricultural Chemistry, National Taiwan University, No. 1, Section 4, Roosevelt Road, Taipei 10617, Taiwan, ROC
}

Received 29 June 2005; received in revised form 30 August 2005; accepted 19 October 2005

\begin{abstract}
Native corn starch was hydrolyzed with $0.36 \% \mathrm{HCl}$ in methanol at 25 and $45{ }^{\circ} \mathrm{C}$ for periods of time up to $240 \mathrm{~h}$. The action of acid penetration and hydrolysis was investigated by confocal laser scanning microscopy (CLSM), scanning electron microscopy (SEM), high-performance anionexchange chromatography (HPAEC) and high-performance size-exclusion chromatography (HPSEC) equipped with viscometry, right-angle laser light scattering (RALLS) and refractive index (RI) detectors. Corn starch hydrolyzed at $45^{\circ} \mathrm{C}$ for $240 \mathrm{~h}$ showed strong intensity of APTS (8-amino-1,3,6-pyrenetrisulfonic acid) fluorescence and sharp growth ring structure. Exocorrosion over the surface of corn starch was only observed on the corn starch hydrolyzed at $25^{\circ} \mathrm{C}$ for $240 \mathrm{~h}$ and observed on all corn starch hydrolyzed at $45^{\circ} \mathrm{C}$. The $M_{\mathrm{w}}$ and $R_{\mathrm{h}}$ of acid-hydrolyzed corn starch decreased with increasing the degree of hydrolysis. The acid hydrolysis rate in methanol of corn starch was mainly dependent on the temperature, which dominated the penetration efficiency of acid.
\end{abstract}

(C) 2005 Elsevier Ltd. All rights reserved.

Keywords: Corn starch; Acid-methanol treatment; Starch granule; Confocal laser scanning microscopy

\section{Introduction}

Starch, the dominant carbohydrate reserve material of higher plants, mainly consists of two types of $\alpha$-D-glucose homopolymers, that is, amylose and amylopectin. Amylose is an essentially linear molecule composed of anhydroglucose units connected through $(1 \rightarrow 4)$ - $\alpha$-linkages with a few $(1 \rightarrow 6)$ $\alpha$-linkages (Buleon, Colonna, Planchot, \& Ball, 1998) and its weight-average molecular weight $\left(M_{\mathrm{w}}\right)$ is approximately $1 \times$ $10^{5}-1 \times 10^{6}$ (Biliaderis, 1998; Buleon et al., 1998; Mua \& Jackson, 1997). Amylopectin is a much larger molecule with $M_{\mathrm{w}}$ of $1 \times 10^{7}-1 \times 10^{9}$ (Yoo \& Jane, 2002) and a heavily branched structure built from about $95 \%(1 \rightarrow 4)-\alpha$ - and $5 \%$ $(1 \rightarrow 6)$ - $\alpha$-linkages (Tester, Karkalas, \& Qi, 2004).

Inside starch granules, the assembly of macromolecules with alternating semi-crystalline clusters and amorphous growth rings is not uniform. Fannon and co-workers (Fannon, Huber, \& BeMiller, 1992) reported the exist of surface pores of corn, sorghum, and millet starch granules and presented the evidences that the internal cavity at the granule helium was

\footnotetext{
* Corresponding author. Tel.: +88623366 4816; fax: +886223633123.

E-mail address: hmlai@ntu.edu.tw (H.-M. Lai).
}

0144-8617/\$ - see front matter (C) 2005 Elsevier Ltd. All rights reserved. doi:10.1016/j.carbpol.2005.10.031 connected to surface pores by channels (Huber \& BeMiller, 1997, 2000). The central region of starch granule surrounding the helium is believed to be less organized (Gray \& BeMiller, 2004; Huber \& BeMiller, 2001) and the starch molecular arrangement at outer layer of granule also seems to be different from the inner portion (Fannon, Gray, Gunawan, Huber, \& BeMiller, 2004; Ziegler, Creek, \& Runt, 2005). Since the considerable heterogeneity within starch granules, the chemical modified starches are influenced by the architecture of starch granules including the way of starch molecules packing inside the granule, the exist of central cavity, and the number of the surface pores and channels, which are depended on the plant origins. The optical sections of corn starch granules, which had been subjected to a short-time treatment with aqueous merbromin solution then examined by CLSM (confocal laser scanning microscopy), indicated the possibility of non-uniform reaction with chemicals during modification (Huber \& BeMiller, 2000).

The typical procedure to prepare acid-hydrolyzed starch may be divided into two ways, according to the acid used. Treatment of native potato starch in water with $15 \% \mathrm{H}_{2} \mathrm{SO}_{4}$ for 30 days at room temperature produces Nageli amylodextrins (Nageli, 1874), whilst immersion starches in $2.2 \mathrm{~N} \mathrm{HCl}$ at elevated temperatures $\left(30-40{ }^{\circ} \mathrm{C}\right)$ results in lintnerised starch (Lintner, 1886). Moreover, Small (1919) prepared the soluble starch by refluxing starch granules in $95 \%$ ethanol containing 
$0.2-1.6 \%(\mathrm{w} / \mathrm{v}) \mathrm{HCl}$ for $6-15$ min to produce low molecular weight dextrin. The acid modification in four different alcohols (methanol, ethanol, 2-propanol, and 1-butanol) or mixtures of alcohols produced starches with different average DP values. The highest DP value was obtained when methanol was used as the reaction medium (Ma \& Robyt, 1987; Robyt, Choe, Fox, Hahn, \& Fuchs, 1996a,b). The different alcohols and the mixtures of alcohols resulted in different concentrations of acid inside the granules (Ma \& Robyt, 1987) and influenced on the availability or the susceptibility of the 'various' $\alpha-(1 \rightarrow 4)$ glycosidic linkages to the reaction of acid (Robyt et al., 1996b).

Recently, Chang and co-workers (Chang, Lin, \& Lii, 2004; Lin, Lee, \& Chang, 2003; Lin, Lii, \& Chang, 2005) reported the influence of acid-alcohol treatment conditions on the granular and molecular levels of waxy maize and potato starches. In this study, the granular and molecular changes of $\mathrm{HCl}$-methanol modified native corn starch were observed by confocal laser scanning microscopy, scanning electron microscopy (SEM), high-performance size-exclusion chromatography (HPSEC), and high-performance anion-exchange chromatography (HPAEC). The findings were discussed and provided the improved knowledge of starch granular structure models from $\sim$ micrometers to $\sim$ nanometers scale.

\section{Materials and methods}

\subsection{Starch and enzyme}

The native corn starch was purchased from Gu Tong Foods Industrial Ltd (Chia-Yi, Taiwan). The corn starch contained $13.52 \%$ moisture and $0.05 \%$ ash, $2.72 \%$ crude fat and trace amount of crude protein on a dry basis, analyzed according to AACC methods 44-15A, 08-01, 30-20, and 46-12 (AACC, 1995). Isoamylase (EC 3.2.1.68) of Pseudomonas amyloderamosa $(59,000 \mathrm{U} / \mathrm{mg})$ was purchased from Hayashibara Biochemical Laboratories, Inc. (Okayama, Japan). All the chemicals used in this study were reagent grade.

\subsection{Preparation of acid-methanol modified starch}

Native corn starch $(250 \mathrm{~g} / \mathrm{l})$ was suspended in anhydrous methanol (purity $>99.9 \%$ ) (Mallinckrodt Baker, Inc., Phillipshurg, NJ, USA) containing $0.36 \% \mathrm{HCl}$. The starch suspension was kept in water bath $\left(25\right.$ or $\left.45^{\circ} \mathrm{C}\right)$ with continuous stirring. To maintain the concentration of $\mathrm{HCl}$, total weight of starch suspensions were recorded daily and re-added the amount of evaporated loss of methanol. Aliquots were withdrawn at different time intervals $(6,12,24,72,120,240 \mathrm{~h})$ and neutralized with $1 \mathrm{M} \mathrm{NaHCO}_{3}$ in ice-bath. The suspension were then centrifuged at $4000 \times g$ for $5 \mathrm{~min}$. The precipitates were washed with $50 \%$ ethanol three times and dried at $40{ }^{\circ} \mathrm{C}$ air-oven for 1 day.

\subsection{Confocal laser scanning microscopy}

Starch granules were stained by using the aminofluorophore 8-amino-1,3,6-pyrenetrisulfonic acid (APTS, Molecular
Probes, OR, USA) according to the method described by Blennow et al. (2003). To elucidate the diffusion of methanol, methanol, instead of water, was used to prepared APTS and $\mathrm{CH}_{3} \mathrm{BNNa}$ solution to stain starch granules for $2 \mathrm{~min}, 15 \mathrm{~h}$, and $36 \mathrm{~h}$.

A confocal laser scanning microscopy (Leica TCS SP2 Confocal Spectral Microscope, Wetzlar, Germany) was equipped with an argon laser and an objective $(100 \times$ Plan apo/1.4 oil). The excitation wavelength was $488 \mathrm{~nm}$ with $20 \%$ capacity and the light detected at the interval from 500 to $600 \mathrm{~nm}$. The format of image was $30 \times 30 \mu \mathrm{m}$ and $512 \times 512$ pixels. During image acquisition, each line was scanned eight times and averaged to reduce noise.

\subsection{Scanning electron microscopy}

Starch granules were mounted on circular aluminum stubs with double sided adhesive tape and coated with gold (Hitachi E101 Ion sputter, Tokyo, Japan). Scanning electron micrographs were taken using a microscope (Hitachi S-2400, Tokyo, Japan). The accelerating voltage was $20 \mathrm{kV}$.

\subsection{Molecular weight distribution determined by a HPSEC- Viscometry-RALLS-RI system}

Starch granules $(10 \mathrm{mg})$ were dissolved in $90 \%$ dimethylsulphoxide (DMSO, $1 \mathrm{ml}$ ) with continuous stirring in a boiling water bath for $1 \mathrm{~h}$ then kept at room temperature for $8 \mathrm{~h}$. The starch dispersion was mixed with four volumes of absolute ethanol and stored at $4{ }^{\circ} \mathrm{C}$ overnight. The ethanol-precipitated starch was separated by centrifugation at $1167 \times g$ for $5 \mathrm{~min}$ and washed with $95 \%$ ethanol three times. To obtain sufficient laser-light scattering and viscosity signals for calculating the molecular weight distribution of starch, the starch pellet from different extent of acid hydrolysis was diluted with different amounts of $0.1 \mathrm{M} \mathrm{NaNO}_{3}$ containing $0.02 \% \mathrm{NaN}_{3}$ and stirred for $30 \mathrm{~min}$ in a boiling water bath. The hot sample solution was filtered through a PVDF membrane filter $(5.0 \mu \mathrm{m})$ (TITAN, NC, USA), then injected into a HPSEC system.

A HPSEC system consists of a Hitachi L-6000 isocratic pump (Hitachi Ltd, Tokyo, Japan) equipped with an on-line degasser (Model 3415 $\alpha$, ERC, Inc., Saitama, Japan), an injection valve (100 $\mu \mathrm{l}$ sample loop, 7725i, Rheodyne, CA, USA), a viscometer detector combined with a right-angle laserlight-scattering (RALLS) detector (Viscoteck Model T-60A Dual Detector, TX, USA) and an Hitachi L-3300RI detector (Hitachi Ltd, Tokyo, Japan). The series interconnection of the viscometer detector and the right-angle laser-light-scattering detector was parallel connected with the RI detector. To monitor the molecular size distribution of acid-methanol modified starch, a TSK gel guard column, and a G5000PW and a G3000PW analytical columns (TOSOH, Tokyo, Japan) were used. The temperature of the columns was maintained at $40{ }^{\circ} \mathrm{C}$ using a column oven (Super CO-150, ENSHINE, Taipei, Taiwan). Temperature of RI detector was set at $37^{\circ} \mathrm{C}$. The water used was distilled-deionized water $(18.2 \mathrm{~m} \Omega \mathrm{cm})$ and the eluent was $0.1 \mathrm{M} \mathrm{NaNO}_{3}$ with $0.02 \% \mathrm{NaN}_{3}$, degassed 
and filtered through a Nylon membrane $(0.45 \mu \mathrm{m})$ (ChromTech, Singapore) before use. The flow rate of mobile phase was $0.5 \mathrm{ml} / \mathrm{min}$. The system was calibrated with a dextran standard (American Polymer Standards Corporation, OH, USA) of known $M_{\mathrm{w}}(236,100 \mathrm{Da})$, intrinsic viscosity $(0.467 \mathrm{dl} / \mathrm{g})$, and $\mathrm{d} n / \mathrm{d} c$ of $0.147 \mathrm{ml} / \mathrm{g}$. The refraction index value of mobile phase was obtained by the reference to the water value of 1.333. The $M_{\mathrm{w}}$ and hydrodynamic radius $\left(R_{\mathrm{h}}\right)$ values of the starches was calculated with OminiSEC software 2.0.3 (Viscoteck Corp., TX, USA). HPSEC determinations were duplicated.

\subsection{Chain length distribution by HPAEC}

Native and acid-hydrolyzed corn starch granules were dissolved in DMSO as described above. The starch pellets were diluted with distilled-deionized water to $5 \mathrm{mg} / \mathrm{ml}$ and stirred for $30 \mathrm{~min}$ in a boiled water bath. After cooling to room temperature, the starch solution $(2 \mathrm{ml})$ was mixed with $2 \mathrm{ml}$ $40 \mathrm{mM}$ acetate buffer $(\mathrm{pH} 3.5)$ and $4 \mu \mathrm{l}$ isoamylase $(5.9 \mathrm{U} / \mu \mathrm{l})$. The mixture was incubated in a water bath at $37{ }^{\circ} \mathrm{C}$ for $3 \mathrm{~h}$ and carefully stirred every hour. The enzymatic reaction was stopped by heating the mixture in a boiling water bath for 10 min. The debranched starch solution was filtered through a PVDF membrane filter $(0.45 \mu \mathrm{m})$ then injected into a HPAEC system. Besides, the acid-hydrolyzed corn starch without isoamylase debranching was also analyzed.

A Dionex Bio-LC system 300 (Sunnyvale, CA, USA) equipped with a BioLC gradient pump and a pulsed amperometric detector (PAD) was used. The filtrated sample was injected $(25 \mu \mathrm{l})$ into a Dionex CarboPac PA1 column. The pulsed potentials and durations were: $E_{1}=0.05 \mathrm{~V}\left(t_{1}=\right.$ $420 \mathrm{~ms}), E_{2}=0.75 \mathrm{~V}\left(t_{2}=180 \mathrm{~ms}\right)$, and $E_{3}=-0.15 \mathrm{~V}\left(t_{3}=\right.$ $360 \mathrm{~ms}$ ) at range 1 (sampling periods, $16.67 \mathrm{~ms}$ ). The eluents $\mathrm{A}$ and $\mathrm{B}$ were $100 \mathrm{mM} \mathrm{NaOH}$ and $100 \mathrm{mM} \mathrm{NaOH}$ in $500 \mathrm{mM}$ $\mathrm{NaOAc}$, respectively. The solutions were degassed with helium by a Dionex degas module. The flow rate was $1 \mathrm{ml} / \mathrm{min}$ and eluent gradient was in a linear gradient of eluent B from 0 to $50 \%$ during $0-70 \mathrm{~min}$, then in a linear gradient to $70 \%$ of eluent B during 70-120 min. The known DP standards including glucose (ChemService, PA, USA), maltotriose, maltotetraose, maltopentaose, and maltohexaose (Fluka, Buchs, Switzerland) were used to calibrate the elution time vs. DP of sugars. HPAEC determinations were repeated three times.

\subsection{Statistical analysis}

The data of chain length distributions were analyzed with SAS software (Version 8.2, SAS Institute, Inc., Cary, NC) and Duncan's test was used to analyze the differences at $5 \%$ confidence level to compare mean values across the treatments.

\section{Results and discussion}

\subsection{Effect of starch granular architecture on diffusion pathway of reagents}

To trace the pathway of methanol diffusion into starch granules, the starch was stained with a methanolic APTS solution for $2 \mathrm{~min}, 15 \mathrm{~h}$, and $36 \mathrm{~h}$ and optical sections at approximately geometric centers of native corn starches were examined by CLSM (Fig. 1). Florophore APTS is a small molecule with $M_{\mathrm{w}} 523.39 \mathrm{~g} / \mathrm{mol}$ and reacts with the reducing end of each starch molecule in a nearly 1:1 stoichoimetry (O'Shea, Samuel, Konik, \& Morell, 1998). The methanolic APTS solution diffused into outer layer of starch granule and passed through channels into central cavity then diffused from cavity and channels outward the granule matrix (Fig. 1a and b). The diffusion appears preferentially from inside out, i.e. from central cavity toward internal part of granule. The region between granular surface and matrix surrounding interior cavity and channels were the last area for reaction to take place (Fig. 1c; Hamunen, 1995; Huber \& BeMiller, 1997). The shorttime treatment $(15,30$, and $60 \mathrm{~s})$ of native corn starch with aqueous merbromin solution revealed the similar diffusion pattern of dye into the hydrated granule matrix through both central cavity and channels (Huber \& BeMiller, 2000).

\subsection{Granular characteristics of acid-treated starches}

To investigate the internal granular structure of corn starch with HCl-methanol modification, the starch was stained with APTS aqueous solution and reacted at $40{ }^{\circ} \mathrm{C}$ for $15 \mathrm{~h}$ (Fig. 2). The morphology, including size, shape or distribution of the channels, cavity and growth rings of starch granules, and fluorescence intensity of corn starches showed no significant differences between native corn starches and those hydrolyzed with $0.36 \% \mathrm{HCl}$-methanol at $25{ }^{\circ} \mathrm{C}$ for 6 and $240 \mathrm{~h}$ (Fig. 2a-c). In fact, the pale green region between central cavity and the outer layer is not always observed in all starch granules
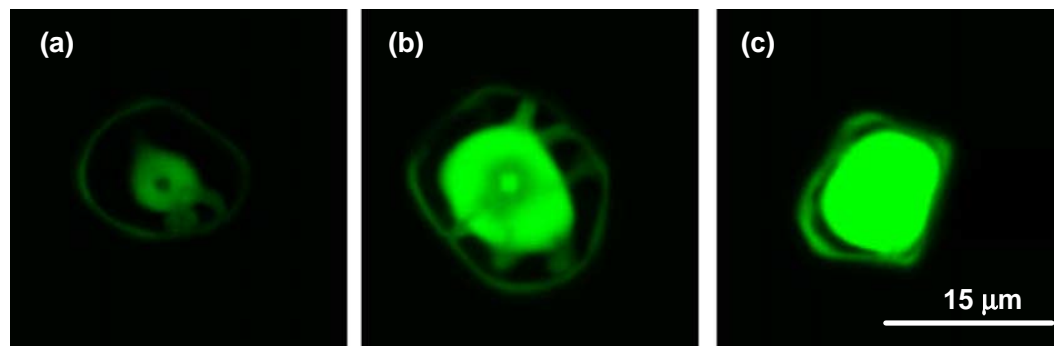

Fig. 1. Confocal laser scanning microscopy optical sections of native corn starch stained with APTS (8-amino-1,3,6-pyrenetrisulfonic acid) in methanol for 2 min (a), $15 \mathrm{~h}(\mathrm{~b})$, and $36 \mathrm{~h}(\mathrm{c})$. The photo-multiplier tube (PMT) of three photos was the same (500). 

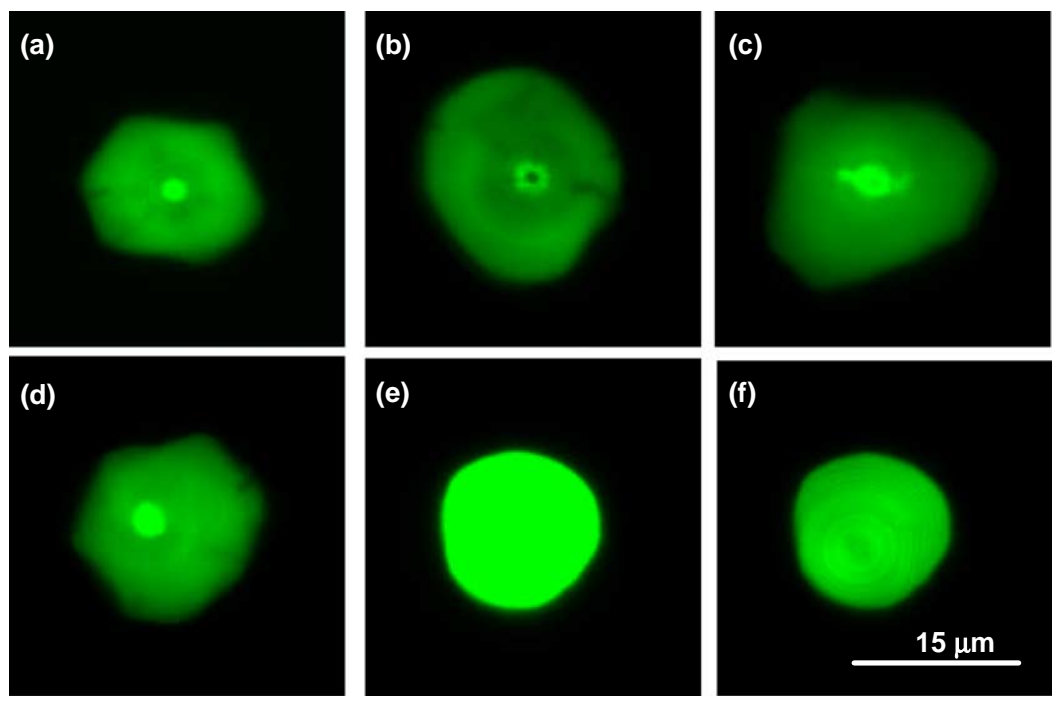

Fig. 2. Confocal laser scanning microscopy optical sections of native corn starch (a), corn starch hydrolyzed with $0.36 \% \mathrm{HCl}$ in methanol at $25{ }^{\circ} \mathrm{C}$ for $6 \mathrm{~h}$ (b) and $240 \mathrm{~h} \mathrm{(c)} \mathrm{and} \mathrm{at} 45^{\circ} \mathrm{C}$ for $6 \mathrm{~h} \mathrm{(d)} \mathrm{and} 240 \mathrm{~h}$ (e and f). The photo-multiplier tube (PMT) of images (a-e) was 500, but image (f) was 450.

(Fig. 2b). The heterogeneity within starch granules might inherent the acid hydrolysis effect. Otherwise, corn starch treated with $0.36 \% \mathrm{HCl}$-methanol at $45^{\circ} \mathrm{C}$ for more than 2 days showed both the increases of fluorescence intensity and the clear growth rings (Fig. 2d and e). The strong fluorescence of corn starch hydrolyzed at $45^{\circ} \mathrm{C}$ for 10 days (Fig. 2e) indicated the increase of reducing end after hydrolysis which reacted with more APTS molecules. It is believed that the acid hydrolysis attacked the amorphous region first and the acid etch resulted in a better contrast between amorphous and semicrystalline layers within starch granules (Fig. 2f).

Native corn starch granules had irregular, polygonal shapes with diameters around $10 \mu \mathrm{m}$ (Fig. 3a). The surface of native corn starch granules was smooth. There were no obvious defects or signs of damages on the surface of starch granules even hydrolyzed with $\mathrm{HCl}$-methanol for $72 \mathrm{~h}$ at $25^{\circ} \mathrm{C}$ (Fig. 3b). However, a slightly rough surface due to corrosion was clearly observed after acid hydrolysis for $240 \mathrm{~h}$ at $25^{\circ} \mathrm{C}$ (Fig. 3c), whereas slight exocorrosion of starch granular surface was observed on the starch granules hydrolyzed at $45^{\circ} \mathrm{C}$ for $6 \mathrm{~h}$ (Fig. 3d). After $12 \mathrm{~h}$ of hydrolysis at $45^{\circ} \mathrm{C}$, part of starch granular surface became rough (Fig. 3e). Serious exocorrosion of starch granular surface and even the destruction of starch granules were observed on the starch extensively hydrolyzed, for example, hydrolyzed for $240 \mathrm{~h}$ (Fig. 3f).
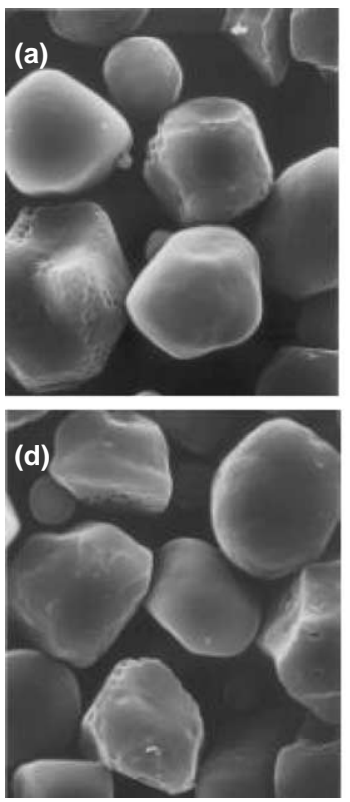
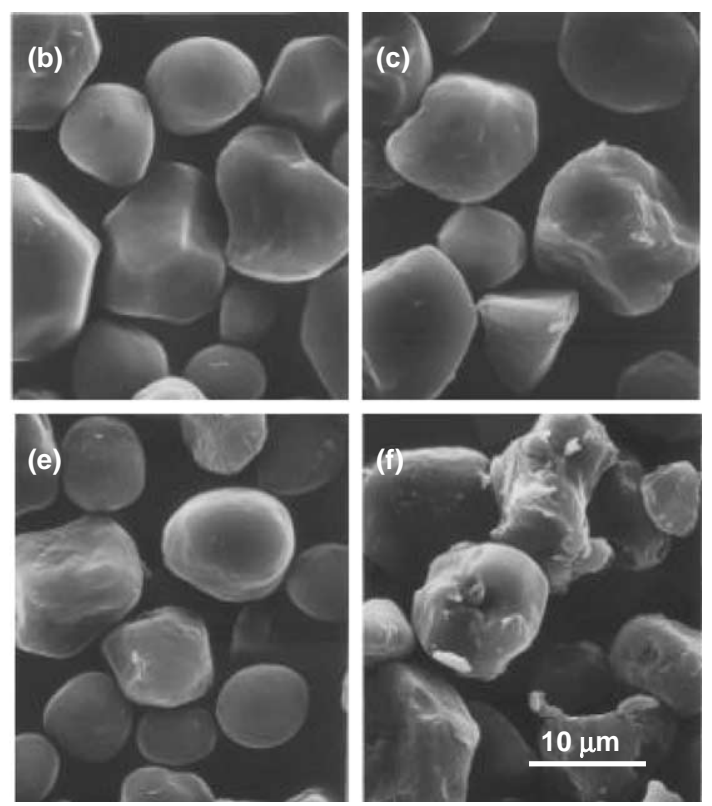

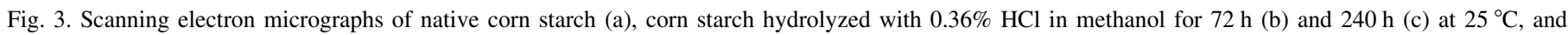
hydrolyzed for $6 \mathrm{~h}(\mathrm{~d}), 12 \mathrm{~h}(\mathrm{e})$, and $240 \mathrm{~h}$ (f) at $45^{\circ} \mathrm{C}$. 


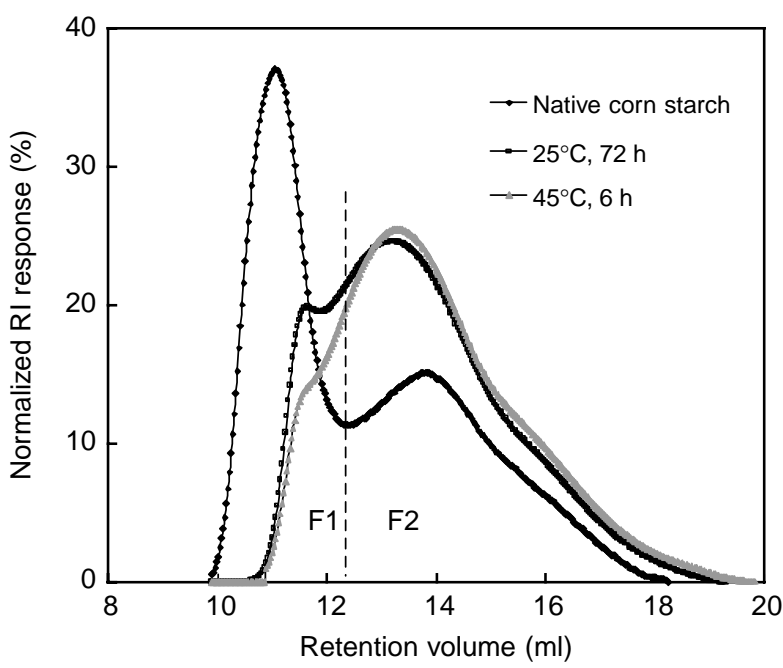

Fig. 4. High-performance size-exclusion chromatograms of native corn starch, corn starch hydrolyzed with $0.36 \% \mathrm{HCl}$ in methanol for $72 \mathrm{~h}$ at $25^{\circ} \mathrm{C}$, and for $6 \mathrm{~h}$ at $45^{\circ} \mathrm{C}$.

\subsection{Molecular characteristics of acid-treated starches}

Molecular size distribution of native corn starch analyzed with HPSEC-Viscometry-RALLS-RI was presented in Fig. 4. Two major fractions were obtained on molecular size distribution of native corn starch. Fraction 1 (F1), a higher molecular weight component, was eluted at lower elution volumes and mainly corresponded to amylopectin. Fraction 2 (F2), a lower molecular weight component, was eluted at higher elution volumes and mainly corresponded to amylose. F1 and F2 of corn starch shifted to a longer retention volume after acid hydrolysis and indicated the decreases of their molecular sizes. When weight fraction of $\mathrm{F} 1$ was plotted vs. hydrolysis time, the corn starch hydrolyzed at $25^{\circ} \mathrm{C}$ showed two different rates (Fig. 5). Two different hydrolysis rates of

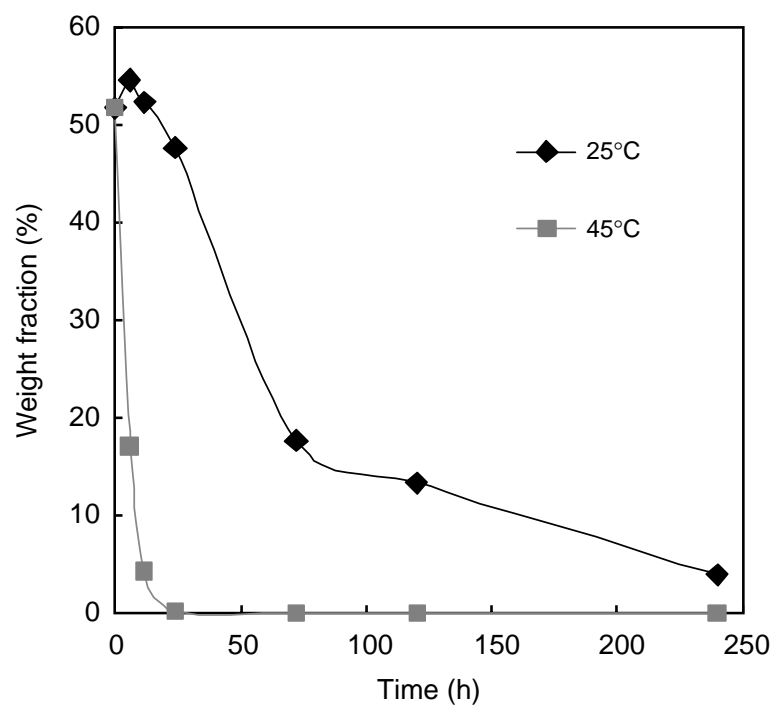

Fig. 5. Comparison of F1 weight fraction (\%) of HCl-methanol hydrolyzed corn starch at 25 and $45^{\circ} \mathrm{C}$. F1 weight fraction was calculated as dividing the integration of the reflection index (RI) signals of F1 in high-performance sizeexclusion chromatograms (Fig. 4) by the total area of the RI signals.

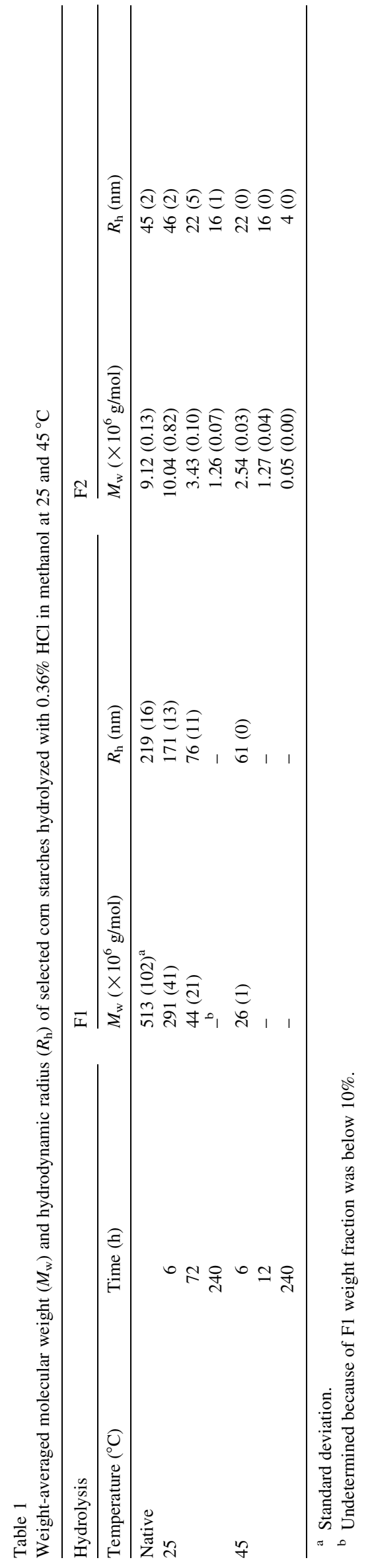




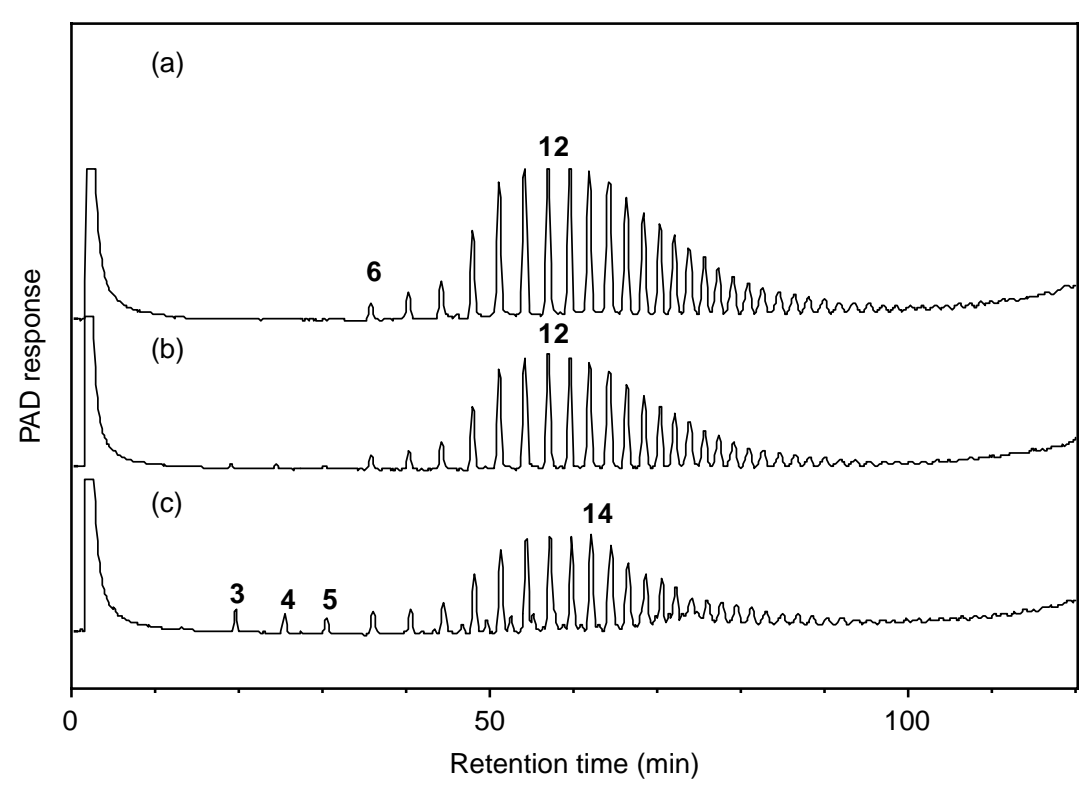

Fig. 6. High-performance anion-exchange chromatograms of isoamylase debranched corn starch (a) and with $0.36 \% \mathrm{HCl}$-methanol treatment at $25{ }^{\circ} \mathrm{C}$ for $240 \mathrm{~h}$ (b) and at $45^{\circ} \mathrm{C}$ for $240 \mathrm{~h}(\mathrm{c})$.

starch hydrolyzed at $25{ }^{\circ} \mathrm{C}$ were mainly due to the diffusion pathway of methanol throughout the starch granule. The first fast rate $(0-72 \mathrm{~h})$ was attributed to the hydrolysis of the amorphous regions surrounding the surface of starch granules, near the channels in the granules, and the internal cavity at the granule helium. As indicated in Fig. 1c, the unstained area was probably the hardest part for acid diffusion. The second slow rate $(72-250 \mathrm{~h})$ was attributed to the hydrolysis of the amorphous regions in the semicrystalline architecture, and the less order regions between the granular surface and the matrix near the cavity and channels. Furthermore, the increased in temperature facilitated the diffusion rate of methanol, the flexibility of starch molecules and the reaction rate of acid hydrolysis. Thus, the corn starch hydrolyzed at $45^{\circ} \mathrm{C}$ showed a very sharp decreasing reaction rate during the first $12 \mathrm{~h}$, so that the F1 was disappeared quickly (Fig. 5).

The reaction of the hydrolysis of the glycosidic linkage inside starch granules are influenced by the following three main factors: (1) the available water molecules, (2) the acid participating in hydrolysis, and (3) the availability and reactivity of the glycosidic linkage. Robyt et al. (1996b) suggested that hydrolysis of the glycosidic linkage in alcoholic solution was occurred with the $10-12 \%$ water originally inside starch granule (factor (1)). The diffusion of methanol into starch matrix determined the local acid content inside the starch granules (factor (2)), while CLSM images (Fig. 1) indicated the reagent flow occurs primarily from central cavity or latterly from channels to starch matrix. The crystallinity or organization of starch molecules affect the availability and activity of the glycosidic linkage (factor (3)). It is believed that the ability of acid diffusing into starch granules at 25 and $45^{\circ} \mathrm{C}$ was different. At $25^{\circ} \mathrm{C}$, acid might only diffuse into the amorphous regions near the surface, channel and central cavity of the corn starch in the first $72 \mathrm{~h}$, then diffuse into the amorphous regions such as the unstained area in Fig. 1c. While, the acid diffused almost throughout the amorphous regions of the starch granules at $45^{\circ} \mathrm{C}$ during very short time. As a result, the elevated reaction temperature from 25 to $45^{\circ} \mathrm{C}$ facilitated the diffusion of acid into the corn starch granules and also increased the reactivity of the glycosidic bond.

Table 1 showed the $M_{\mathrm{w}}$ and $R_{\mathrm{h}}$ of F1 and F2 of starch with different extent of acid hydrolysis. The $M_{\mathrm{w}}$ of amylopectin obtained in this study $\left(5.13 \pm 1.02 \times 10^{8} \mathrm{~g} / \mathrm{mol}\right)$ closed to the reported value $\left(4.9 \pm 0.8 \times 10^{8} \mathrm{~g} / \mathrm{mol}\right)$ of common corn starch obtained by Yoo and Jane (2002), but higher than the value $\left(2.43 \pm 0.08 \times 10^{8} \mathrm{~g} / \mathrm{mol}\right)$ reported by Han and Lim (2004a). Differences between these results can be attributed to the sources of corn starches, the HPSEC system and starch preparation methods. Han and Lim (2004a,b) reported that excess mechanical votexing, stirring or heating used to prepared starch dispersion significantly affected molecular weight measurement. The use of $90 \%$ DMSO as solvent with the proper combination of $1 \mathrm{~h}$ boiling and subsequent stirring at room temperature for $8 \mathrm{~h}$ (the same preparation in this study) dissolved $98 \%$ starch and minimized the chain degradation (Han \& Lim, 2004a). Moreover, the $R_{\mathrm{h}}$ of amylopectin of native corn starch was $219 \pm 16 \mathrm{~nm}$ (Table 1). $R_{\mathrm{h}}$ is considered to be related with the end-to-end size of the molecule in solution (Wyatt, 1993). The weight-average molecular weight of amylose obtained in this study $\left(9.12 \pm 0.13 \times 10^{6} \mathrm{~g} / \mathrm{mol}\right)$ was higher than the value $\left(3.13 \pm 0.08 \times 10^{6} \mathrm{~g} / \mathrm{mol}\right)$ reported by Han and Lim (2004a). The $R_{\mathrm{h}}$ of amylose of native corn starch was $45 \pm 2 \mathrm{~nm}$ (Table 1). The $M_{\mathrm{w}}$ of F1 and F2 of corn starch hydrolyzed at 25 and $45^{\circ} \mathrm{C}$ decreased with increasing in the reaction time of acid hydrolysis (Table 1). The faster $M_{\mathrm{w}}$ decreasing rate of F1 than F2 was attributed to the degraded both amylopectin and amylose that integrated into F2. After hydrolyzed at $45^{\circ} \mathrm{C}$ for $240 \mathrm{~h}$, the $M_{\mathrm{w}}$ and $R_{\mathrm{h}}$ of corn starch were $50,000 \mathrm{~g} / \mathrm{mol}$ and $4 \mathrm{~nm}$, respectively. 

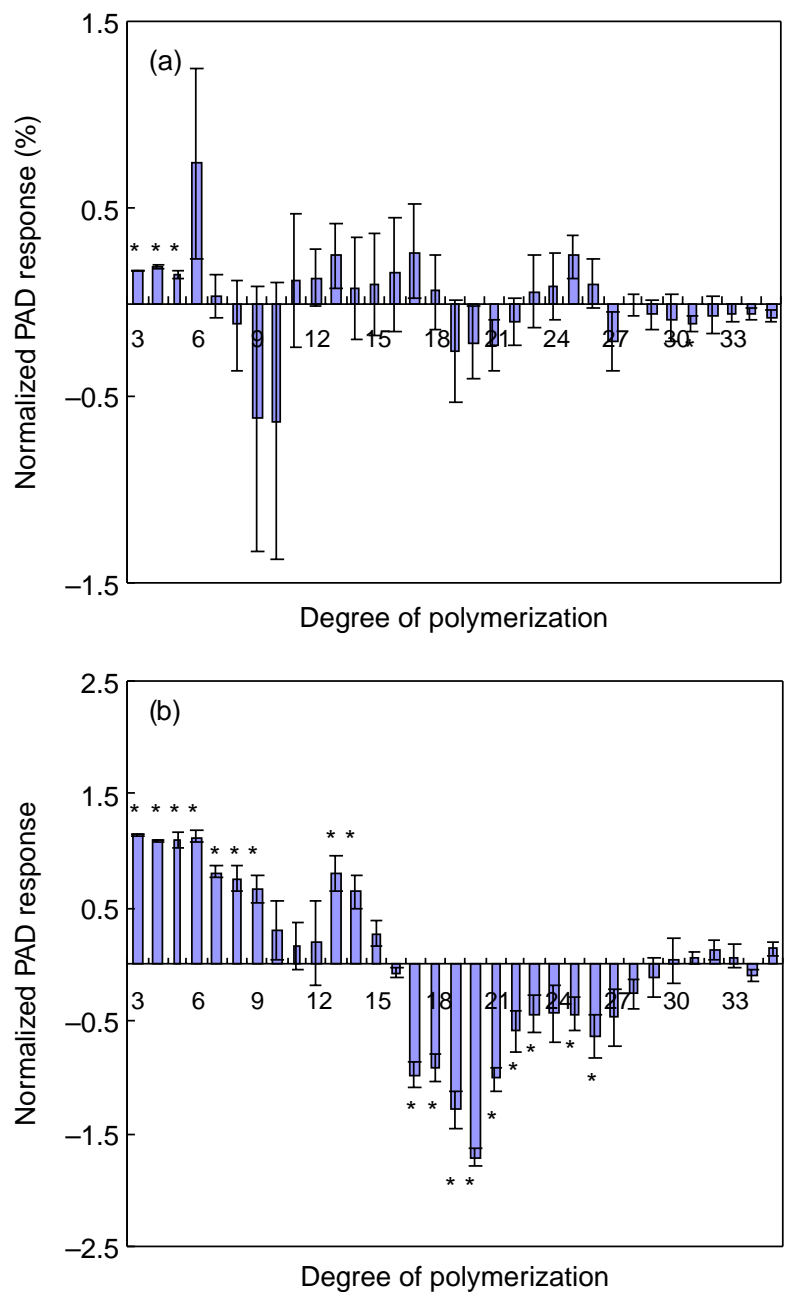

Fig. 7. Differences in percent distribution of high-performance anion-exchange chromatograms of isoamylase debranched corn starch and hydrolyzed with $\mathrm{HCl}$-methanol at $25^{\circ} \mathrm{C}$ for $240 \mathrm{~h}$ (a) and at $45^{\circ} \mathrm{C}$ for $240 \mathrm{~h}$ (b). The percent distributions above and below the line represented the increases and decreases of the percentages of distribution after acid hydrolysis, respectively. Symbol (*) above and below the bar meant the differences between the determinations before and after acid hydrolysis were significant.

\subsection{Chain length distribution of starch}

Fig. 6 showed the chain length distribution of isoamylase debranched corn starch with different degree of acid hydrolysis. The short chains $(\mathrm{DP}<6)$ presented in HPAEC chromatograms (Fig. $6 \mathrm{~b}$ and c) of corn starch with acid hydrolysis was also found in other studies (Jane, Wong, \& McPherson, 1997; Nakazawa \& Wang, 2003). These short chains attributed to partially hydrolysis of glycosidic linkage in the amorphous regions. Differences in percentage distribution of HPAEC chromatograms of isoamylase debranched corn starch with acid hydrolyzed at 25 and $45^{\circ} \mathrm{C}$ for $240 \mathrm{~h}$ were presented in Fig. 7. The DP 3, 4, 5 of corn starch treated at $25{ }^{\circ} \mathrm{C}$ for $240 \mathrm{~h}$ (Fig. 7a) were significantly increased and the DP 31 was slightly decreased. The populations of short chains with DP 3-9 and DP 13 and 14 increased, whereas the population of DP 17-26 significantly decreased after hydrolyzed at $45^{\circ} \mathrm{C}$ for $240 \mathrm{~h}$ (Fig. 7b). Since the crystalline regions

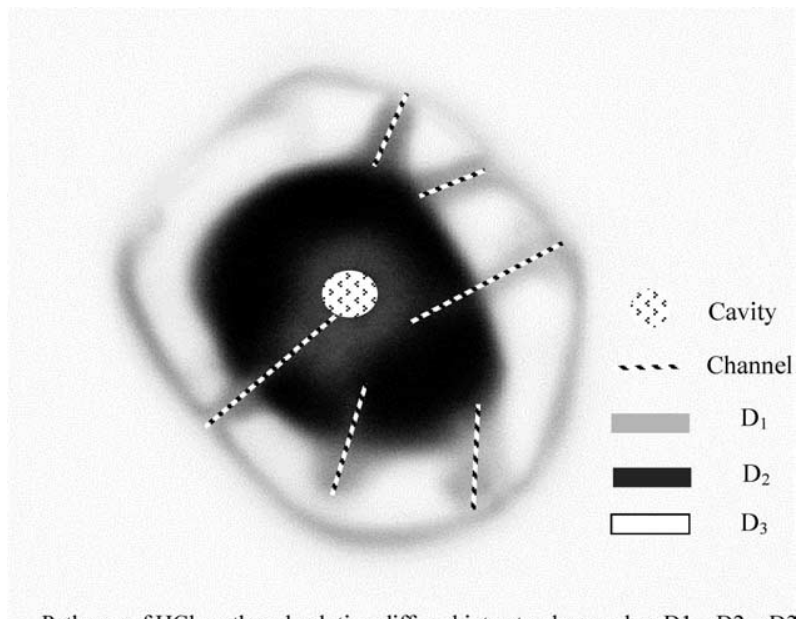

Pathway of HCl-methanol solution diffused into starch granules: D1 $\rightarrow \mathrm{D} 2 \rightarrow \mathrm{D} 3$

Fig. 8. Diagram to illustrate the possible diffusion pathway of HCl-methanol solution into starch granule. $D_{1}$ : the granular matrix surrounding cavity and channels, $D_{2}$ : the intermediate organized area, and $D_{3}$ : dense packed layer beneath the surface of starch granule.

of the starch formed by clusters of $A$ and $B_{1}$ chains of amylopectin, the amorphous regions of the $\mathrm{B}_{2}, \mathrm{~B}_{3}, \mathrm{~B}_{4}$ chains of amylopectin linking several crystalline regions were preferentially attacked and degraded into short chains by acid (Jane et al., 1997; Wang \& Wang, 2001).

\subsection{A proposed model of HCl-methanol hydrolysis on starch influenced by starch granular architecture}

The heterogeneity and complexity of starch structure within granules influence the acid modification of starch molecules. $\mathrm{HCl}$-methanol solution primarily diffused from the surface of starch granules, passed through the channels to the cavity and lateral diffused from cavity and channels throughout the granule matrix. From the diffusion process, the matrix of native corn starch granules was supposed to be divided into three regions: the granule matrix surrounding cavity and channels $\left(D_{1}\right)$, dense packed layer beneath the surface $\left(D_{3}\right)$, and the intermediate organized area $\left(D_{2}\right)$ (Fig. 8). The mild hydrolysis condition of $0.36 \% \mathrm{HCl}$-methanol solution diffused into starch matrix with different rates due to the different structural organizations. The glycosidic linkage within the amorphous region and around the less-organized branching point was preferentially attacked by acid.

\section{Conclusion}

Starch architecture features possibly dictated the acid hydrolysis model within starch granules. The CLSM images of native corn starch stained with APTS for different time periods revealed the influence of diffusion process on chemical modification. The elevated temperature not only increased the reactivity of the hydrolysis of the glycosidic linkage, but also facilitated the diffusion of acid solution throughout starch matrix. The glycosidic bond surrounding the branching point in 
the amorphous region was considered preferentially attacked and degraded by acid since the organization of the molecules in this area is more disordered. The HCl-methanol treatment highlights some possible molecular and granular structure of native corn starch and the characteristics of $0.36 \% \mathrm{HCl}$ methanol hydrolyzed at 25 and $45^{\circ} \mathrm{C}$.

\section{Acknowledgements}

This work was supported by the grant NSC93WFA0101008 from the National Science Council, Taipei, Taiwan.

\section{References}

American Association of Cereal Chemists (1995). Approved methods of the AACC, 9th ed. Method 44-15A, 08-01, 30-20 and 46-12. St. Paul, Minnesota: American Association of Cereal Chemists, Inc.

Biliaderis, C. G. (1998). Structures and phase transitions of starch polymers. In R. H. Walter (Ed.), Polysaccharide association structures in foods (pp. 57168). New York: Marcel Dekker.

Blennow, A., Hansen, M., Schulz, A., Jorgensen, K., Donald, A. M., \& Sanderson, J. (2003). The molecular deposition of transgenically modified starch in the starch granule as imaged by functional microscopy. Journal of Structural Biology, 143, 229-241.

Buleon, A., Colonna, P., Planchot, V., \& Ball, S. (1998). Starch granules: structure and biosynthesis. International Journal of Biological Macromolecules, 23, 85-112.

Chang, Y. H., Lin, J. H., \& Lii, C. Y. (2004). Effect of ethanol concentration on the physicochemical properties of waxy corn starch treated by hydrochloric acid. Carbohydrate Polymers, 57, 89-96.

Fannon, J. E., Gray, J. A., Gunawan, N., Huber, K. C., \& BeMiller, J. N. (2004). Heterogeneity of starch granules and the effect of granule channelization on starch modification. Cellulose, 11, 247-254.

Fannon, J. E., Huber, R. J., \& BeMiller, J. N. (1992). Surface pores of starch granules. Cereal Chemistry, 69, 284-288.

Gray, J. A., \& BeMiller, J. N. (2004). Development and ultilization of reflectance confocal laser scanning microscopy to locate reaction sites in modified starch granules. Cereal Chemistry, 81, 278-286.

Hamunen, A. (1995). Distribution of nitrogen in the cationized potato starch granule. Starch/Starke, 47, 215-219.

Han, J. A., \& Lim, S. T. (2004a). Structural changes of corn starches by heating and stirring in DMSO measured by SEC-MALLS-RI system. Carbohydrate Polymers, 55, 265-272.

Han, J. A., \& Lim, S. T. (2004b). Structural changes in corn starches during alkaline dissolution by votexing. Carbohydrate Polymers, 55, 193-199.

Huber, K. C., \& BeMiller, J. N. (1997). Visualization of channels and cavities of corn and sorghum starch granules. Cereal Chemistry, 74, 537-541.

Huber, K. C., \& BeMiller, J. N. (2000). Channels of maize and sorghum starch granules. Carbohydrate Polymers, 41, 269-276.
Huber, K. C., \& BeMiller, J. N. (2001). Location of sites of reaction within starch granules. Cereal Chemistry, 78, 173-180.

Jane, J. L., Wong, K. S., \& McPherson, A. E. (1997). Branch-structure difference in starches of A- and B-type patterns revealed by their Naegeli dextrins. Carbohydrate Research, 300, 219-227.

Lin, J. H., Lee, S. Y., \& Chang, Y. H. (2003). Effect of acid-alcohol treatment on the molecular structure and physicochemical properties of maize and potato starches. Carbohydrate Polymers, 53, 475-482.

Lin, J. H., Lii, C. Y., \& Chang, Y. H. (2005). Change of granular and molecular structures of waxy maize and potato starches after treated in alcohols with or without hydrochloric acid. Carbohydrate Polymers, 59, 507-515.

Lintner, C. J. (1886). Studien uber diastase. Journal fur Praktis Chemie, 34, 378-386.

Ma, W. P., \& Robyt, J. F. (1987). Preparation and characterization of soluble starches having different molecular sizes and composition, by acid hydrolysis in different alcohols. Carbohydrate Research, 166, 283-297.

Mua, J. P., \& Jackson, D. S. (1997). Fine structure of corn amylose and amylopectin fractions with various molecular weights. Journal of Agricultural and Food Chemistry, 45, 3840-3847.

Nakazawa, Y., \& Wang, Y. J. (2003). Acid hydrolysis of native and annealed starches and branch-structure of their Naegeli dextrins. Carbohydrate Research, 338, 2871-2882.

Nageli, C. W. (1874). Beitage zur naheren kenntniss der starke group. Annalen der chemie, 173, 218-227.

O'Shea, M. G., Samuel, M. S., Konik, C. M., \& Morell, M. K. (1998). Fluorophore-assisted carbohydrate electrophoresis (FACE) of oligosaccharides: Efficiency of labeling and high-resolution separation. Carbohydrate Research, 307, 1-12.

Robyt, J. F., Choe, J. Y., Fox, J. D., Hahn, R. S., \& Fuchs, E. B. (1996a). Acid modification of starch granules in alcohols: effects of temperature, acid concentration, and starch concentration. Carbohydrate Research, 281, 203218.

Robyt, J. F., Choe, J. Y., Fox, J. D., Hahn, R. S., \& Fuchs, E. B. (1996b). Acid modification of starch granules in alcohols: reaction in mixtures of two alcohols combined in different ratios. Carbohydrate Research, 283, 141150.

Small, J. C. (1919). A method for the preparation of soluble starch. Journal of American Chemical Society, 41, 113-120.

Tester, R. F., Karkalas, J., \& Qi, X. (2004). Starch—composition, fine structure and architecture. Journal of Cereal Science, 39, 151-165.

Wang, L., \& Wang, Y. J. (2001). Structures and physicochemical properties of acid-thinned corn, potato and rice starches. Starch/Starke, 53, 570-576.

Wyatt, P. J. (1993). Light scattering and the absolute characterization of macromolecules. Analytica Chimica Acta, 272, 1-4.

Yoo, S. H., \& Jane, J. L. (2002). Molecular weights and gyration radii of amylopectins determined by high-performance size-exclusion chromatography equipped with multi-angle laser-light scattering and refractive index detectors. Carbohydrate Polymers, 49, 307-314.

Ziegler, G. R., Creek, J. A., \& Runt, J. (2005). Spherulitic crystallization in starch as a model for starch granule initiation. Biomacromolecules, 6 , 1547-1554. 